\title{
Experimental and numerical study of the dynamic failure behavior of rock materials subjected to various impact loads
}

\author{
H. M. Kang ${ }^{1}$, M. S. Kang ${ }^{1}$, M. S. Kim ${ }^{1}$, H. K. Kwak ${ }^{2}$, L. J. Park \\ \& S. H. Cho ${ }^{1}$ \\ ${ }^{1}$ Department of Mineral Resources and Energy Engineering, \\ Chon-Buk National University, Korea \\ ${ }^{2}$ Korea Advanced Institute of Science and Technology, Korea \\ ${ }^{3}$ Agency for Defence Development (ADD), Korea
}

\begin{abstract}
An understanding of the effect of strain rate on the dynamic failure and mechanical properties of rock materials is important in the design of rock structures against missile impact or the penetration analysis of projectiles into rock mass. In this study, a pulse shape-controlled Split Hopkinson Pressure Bar system was used to impact rock materials. The impact velocity of the impact bar had been increased to $5 \mathrm{~m} / \mathrm{sec}$ from $30 \mathrm{~m} / \mathrm{sec}$ and complete compressive stressstrain curves were obtained to investigate the effect of strain rate on the dynamic failure of the rock materials. The micro-focus X-ray computerized tomography was used to scan the tested samples and the failure process of rock materials were discussed. The numerical simulations on SHPB tests of rock materials were carried out with the explicit finite element software ANSYS LS-DYNA. The incident stress waveforms obtained from the SHPB test are directly applied to the input into the end side of the incident bar. The numerical stress-strain curves are compared with the experimental curves with a different strain rate.

Keywords: limestone, dynamic fracture behavior, SHPB, X-Ray CT, LS-DYNA, JHC model.
\end{abstract}




\section{Introduction}

An understanding of the effect of strain rate on the dynamic failure and mechanical properties of rock materials is important in the design of rock structures against missile impact or the penetration analysis of projectiles into the rock mass.

Recently a number of studies of dynamic failure properties-strain rate dependency of brittle materials have been performed by means of mechanical loading apparatuses which have wide range loading rate capacity. Split Hopkinson pressure bars (SHPB) technique is one of widely used apparatuses to investigate the strain rate dependency of material properties [1]. SHPB techniques allow relatively uniform deformation conditions with very high strain rates in uni-axial compression tests [2-5]. The strain rate dependencies of strength of rock materials were applied to determination of constitutive model parameters required for numerical simulations of impact penetrating and blast fracturing. Various models have been used for impact problems and rock blasting including elastic, Mohr-Coulomb model, Von Mises, JohnsonHolmquist concrete (JHC) and Johnson-Holmquist (JH) [6, 7].

In this study, the stress-strain curves of limestone under various impacts loading rate were obtained by SHPB tests adapting pulse shaping technique. Micro focus X-ray CT scanner was used non-destructively to observe the fracture patterns of tested samples under several loading rates. The SHPB tests of limestone were simulated with ANSYS LS-DYNA implementing JHC models. Sensitivities of JHC model parameters on the stress-strain behavior were examined by means of numerical SHPB tests.

\section{Experiments}

\subsection{Sample preparations}

Rock blocks were cored $34 \mathrm{~mm}$ diameter and cut to $17 \mathrm{~mm}$ length for SHPB tests. Deviation of the flatness of the end sides of the samples are less than $10 \mu \mathrm{m}$. Figure 1 shows limestone samples for SHPB compression tests.

Table 1 shows physical properties of the limestone samples. Elastic wave velocities of the rock samples were measured by Ultrasonic Velocity Measuring Equipment set-up. Static uni-axial compression strength was $99 \mathrm{MPa}$ and Brazilian tensile strength was 4.12 $\mathrm{MPa}$.

\subsection{Experimental set-up and results}

The SHPB was suggested by Kolsky in 1949 to investigate dynamic properties of various materials under 100 10000/s strain rate [8]. In SHPB test, during the test stress uniformity is needed before starting failures in samples. In this study, pulse shaping techniques with a thin metal disc were employed into the SHPB set-up.

Figure 2 show description of stress waves on a sample between incident and transmitted bars. When incident waves $\varepsilon_{\mathrm{I}}$ reach to the interfaces, incident waves 


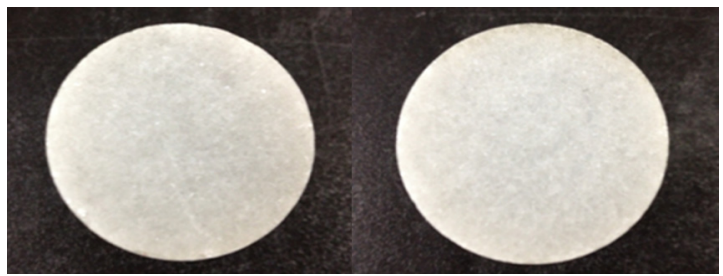

JL-DC-1

JL-DC-2

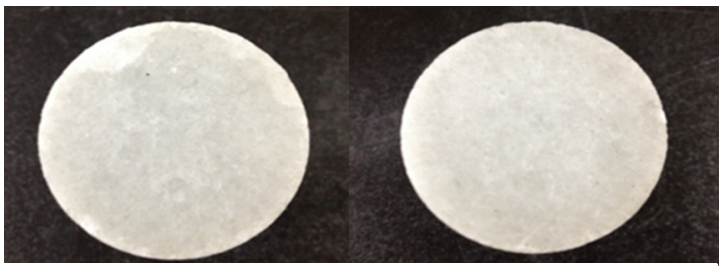

JL-DC-3

JL-DC-4

Figure 1: $\quad$ Limestone samples for dynamic uni-axial compression tests using the SHPB system.

Table 1: $\quad$ Physical properties of limestone.

\begin{tabular}{|c|c|c|c|c|c|c|}
\hline $\begin{array}{c}\text { Density } \\
\left(\mathrm{kg} / \mathrm{m}^{3}\right)\end{array}$ & $\begin{array}{c}\text { Young's } \\
\text { modulus } \\
E \\
(\mathrm{GPa})\end{array}$ & $\begin{array}{c}\text { Poisson's } \\
\text { ratio } \\
v\end{array}$ & $\begin{array}{c}\text { P wave } \\
\text { velocity } \\
(\mathrm{m} / \mathrm{s})\end{array}$ & $\begin{array}{c}\text { S wave } \\
\text { velocity } \\
(\mathrm{m} / \mathrm{s})\end{array}$ & $\begin{array}{c}\text { Uni-axial } \\
\text { compressive } \\
\text { strength } \\
S_{c}^{s} \\
(\mathrm{MPa})\end{array}$ & $\begin{array}{c}\text { Brazilian } \\
\text { tensile } \\
\text { strength } \\
S_{t}^{s} \\
(\mathrm{MPa})\end{array}$ \\
\hline 2699.52 & 41.14 & 0.17 & 5931.58 & 3389.47 & 99 & 4.12 \\
\hline
\end{tabular}

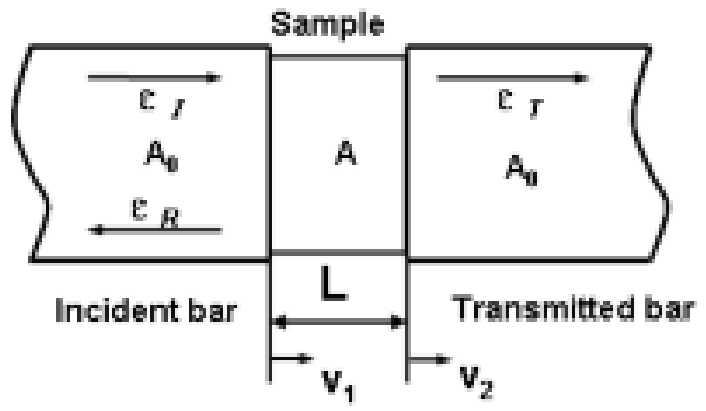

Figure 2: Description of stress waves on the bars. 
separates to reflected waves $\varepsilon_{\mathrm{R}}$ and transmission waves $\varepsilon_{\mathrm{T}}$ according to the difference of impedance.

The stress, strain rate and strain can be calculated with following Holmquist equations [6]

$$
\begin{gathered}
\sigma=\frac{\mathrm{A}_{0}}{\mathrm{~A}} \mathrm{E}_{0} \varepsilon_{\mathrm{T}} \\
\dot{\varepsilon}=-\frac{2 \mathrm{C}_{0}}{\mathrm{~L}} \varepsilon_{\mathrm{R}} \\
\varepsilon=-\frac{2 \mathrm{C}_{0}}{\mathrm{~L}} \int_{0}^{\mathrm{t}} \varepsilon_{\mathrm{R}} \mathrm{d}_{\mathrm{t}}
\end{gathered}
$$

where $A_{0}, E_{0}$ and $C_{0}$ means diameters, elastic modulus and elastic velocity of steel bars respectively. $A$ and $L$ refer to sample diameter and sample length.

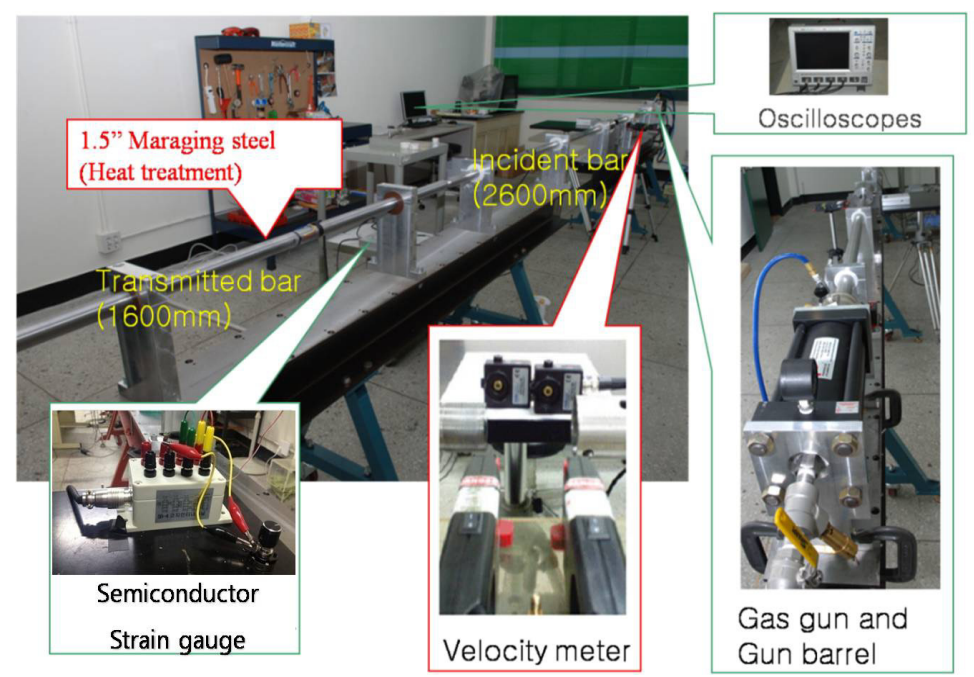

Figure 3: $\quad$ SHPB experimental set up.

Figure 3 shows SHPB equipment and data acquisition system. In front of incident bar, high speed photodiode and laser are placed to check impact velocity of impact bar. Gas chamber has 1000psi capacity and normally the air pressure is set up to 150 psi for safety. Semi-conduct strain gauges were attached at the centre of incident bar and transmitted bar to obtain the strain waves.

Diameter of impact bar, incident bar and transmission bar are $37 \mathrm{~mm}$ and each bar has 200mm, 2600mm, 1600mm respectively. Materials of bars are Maraging steel and elastic wave velocity is $5756 \mathrm{~m} / \mathrm{s}$, density is $7.81 \mathrm{~g} / \mathrm{cc}$, Young's modulus is $195 \mathrm{GPa}$. 
Table 2: $\quad$ Compression test conditions.

\begin{tabular}{|c|c|c|c|c|}
\hline Sample no. & $\begin{array}{c}\text { Length } \\
(\mathrm{mm})\end{array}$ & $\begin{array}{c}\text { Diameter } \\
(\mathrm{mm})\end{array}$ & $\begin{array}{c}\text { Pulse shaper } \\
(囚 / L \mathrm{~mm})\end{array}$ & $\begin{array}{c}\text { Gas pressure } \\
(\mathrm{psi})\end{array}$ \\
\hline JL-DC-1 & 18 & 37.3 & $10 / 0.55$ & 10 \\
\hline JL-DC-2 & 17.98 & 37 & $10 / 0.55$ & 20 \\
\hline JL-DC-3 & 18 & 37 & $10 / 0.55$ & 30 \\
\hline JL-DC-4 & 17.99 & 37.2 & $10 / 0.55$ & 40 \\
\hline
\end{tabular}

This study adopted the pulse shaping technique to achieve the stress uniformity in the samples before occurrence of failure. Thin copper disk is placed at the impact bar-incident bar interface. In order to test the dynamic fracture strength and fracture face the striker bar speed was controlled from $11 \mathrm{~m} / \mathrm{s}$ to $21 \mathrm{~m} / \mathrm{s}$ step by step and all of the data was collected using oscilloscope. Table 2 show the test conditions of dynamic compression tests.

Figure 4 shows the dynamic stress-strain curves of limestone samples which were calculated using Eqs (1) and (3). In the graph, JL-DC-1 represents the stress-strain curve for a limestone sample with the strike velocity of $11 \mathrm{~m} / \mathrm{sec}$. The curve shows almost elastic behaviour with the permanent plastic strain of 0.005 . The rock sample remained whole with a number of micro cracks. JL-DC2 shows the stress-strain curve for a limestone sample with the strike velocity

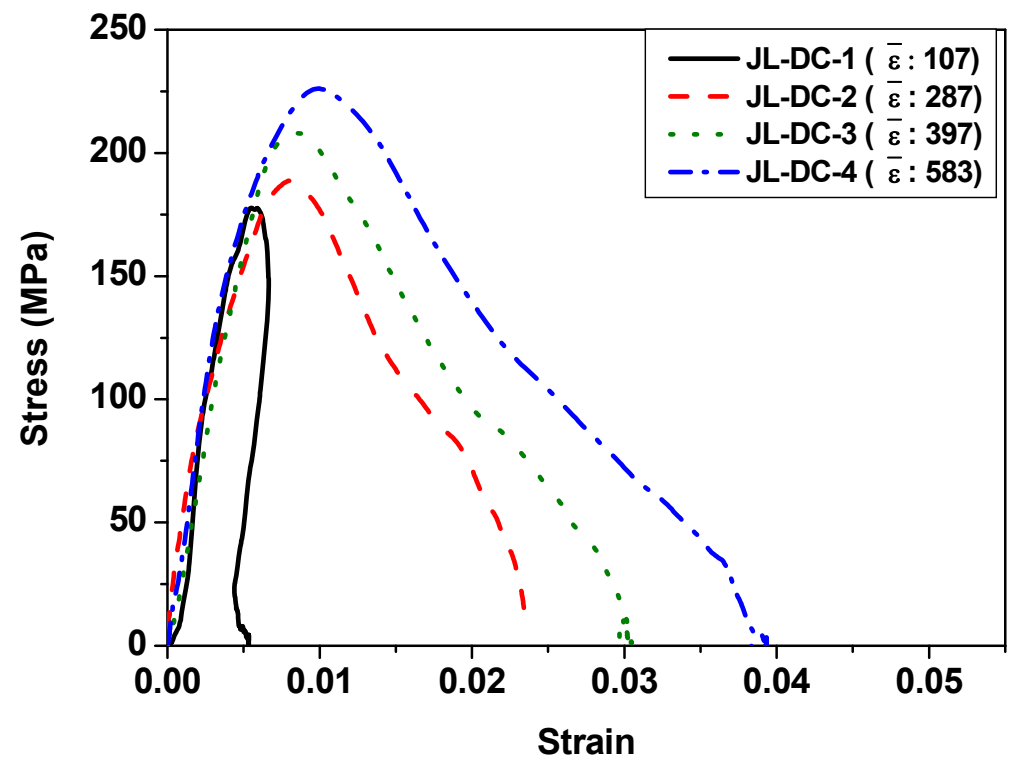

Figure 4: Dynamic stress-strain curves of limestone samples. 
of $15 \mathrm{~m} / \mathrm{sec}$. The curve increases with increasing strain as the same slope with JLDC-1 sample and shows strain-softening behaviour after the stress reach at $185 \mathrm{MPa}$. The rock sample was broke into several piece. JL-DC-3 also represents the stress-strain curve for limestone sample with the strike velocity of $18 \mathrm{~m} / \mathrm{sec}$. The peak stress reached up to around $210 \mathrm{MPa}$ and the permanent strain was 0.03 . The sample was overall broken as very small fragments. JL-DC4 shows the curve of the sample impacted with the strike velocity of $21 \mathrm{~m} / \mathrm{sec}$. The stress marked $225 \mathrm{MPa}$ at the peak and showed strain-softening behaviour with permanent strain of 0.04 . The sample was broken into very small pieces. It is worth noting that the stress-strain curves of limestone are similar to traditional stress-strain curve of soft rocks which show Class I failure patterns. Table 3 summarizes the results of SHPB dynamic compression tests of limestone samples.

Table 3: $\quad$ Results of dynamic compression tests.

\begin{tabular}{|c|c|c|c|}
\hline Sample no. & $\begin{array}{c}\text { Impact velocity } \\
(\mathrm{m} / \mathrm{s})\end{array}$ & $\begin{array}{c}\text { Strain rate } \\
(1 / \mathrm{s})\end{array}$ & $\begin{array}{c}\text { Peak failure } \\
\text { stress } \\
(\mathrm{MPa})\end{array}$ \\
\hline JL-DC-1 & 11.15 & 107 & 177.68 \\
\hline JL-DC-2 & 15.08 & 287 & 188.82 \\
\hline JL-DC-3 & 17.98 & 397 & 208.04 \\
\hline JL-DC-4 & 21.28 & 583 & 226.10 \\
\hline
\end{tabular}

\subsection{Observation fracture pattern of fracture pattern}

In order to discuss the fracture patterns of limestone samples which experienced the impacts in SHPB tests, the tested samples were scanned by Micro-focus Xray CT tomography scanner, SMX-225CT-SV3 (Shimadzu Co.). The maximum voltage, current, tube current, matrix size, detector size are $225 \mathrm{kV}, 1 \mathrm{~mA}, 118 \mathrm{kV}$, 100 us, 512x512pixel, 0.9inch respectively. The number of scan slices was 180 and thickness of the slices was $0.101 \mathrm{~mm}$.

The scan machine has a cone-beam function which is able to obtain three dimensional images with one time scanning. Focus size of the scanner is minimum $4 \mu \mathrm{m}$.

Figures 5 (a) and (b) show X-ray CT images of samples which impacted with the strike velocity of $12 \mathrm{~m} / \mathrm{sec}$ and $14 \mathrm{~m} / \mathrm{sec}$, respectively. The darkness of color in the sample images indicates the fractures or cracks. The main cracks which have relatively large crack opening are visible around the out surface and minor small cracks occur throughout whole area. The number and opening of cracks increased with strike velocity increment. It seems that the visible cracks in Figure. 5 produced the permanent plastic strains which were represented in the stress-strain curves in Figure. 4. 


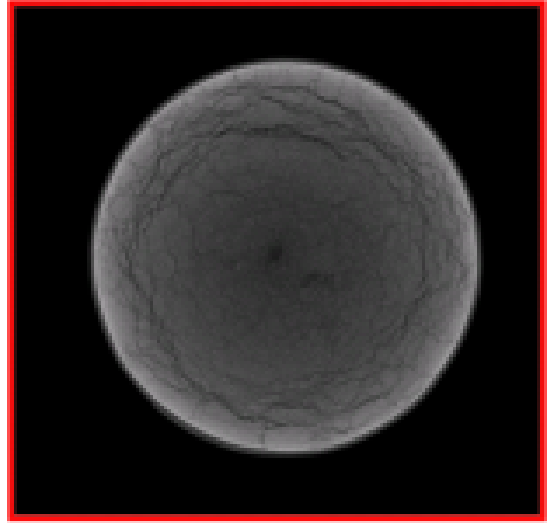

(a)

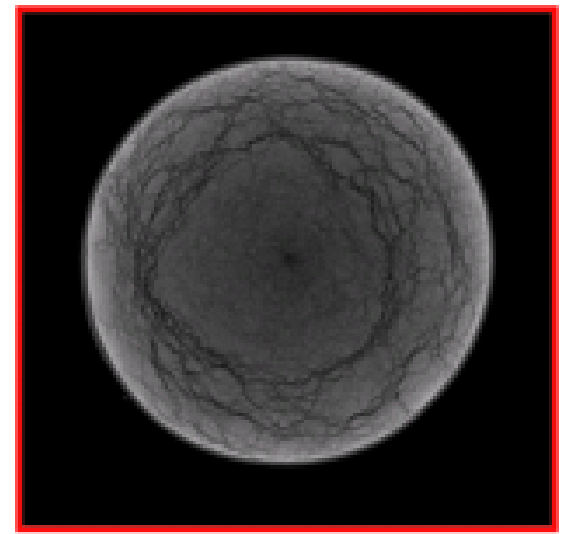

(b)

Figure 5: $\quad$ Selected cross sectional images from 3-D CT images of the tested samples. (a) Impact velocity of $12 \mathrm{~m} / \mathrm{sec}$; (b) Impact velocity of $14 \mathrm{~m} / \mathrm{sec}$.

\section{Physical modelling of SHPB tests}

Figures 4 showed traditional stress-strain curves for Class I failure materials. Normally solid materials such as limestone, tuff, sandstone, mudstone and concrete representing shear failure under compression are classified as Class I failure patters. In this study, LS-DYNA was used for simulating SHPB dynamic impact test of limestone rocks with assumption of the wave propagation theory. The incident wave, reflected and transmitted waves can be calculated by the simulation.

Figures 6 show the finite element model of SHPB test and applied stress curve obtained from the experiments. The sample model for limestone between the incident and transmitted bars is defined as JHC concrete model which is usually used for simulating dynamic compression behaviour of concrete. The model used the hexagonal geometry mesh and the solid elements (solid 164) in LS-DYNA program.

Original JHC material models are suggested by Holmquist et al. [6] were modified to simulate approximately the stress-strain behaviors of limestone as described in Chapter 2. In order to investigate the sensitivity of stress-strain behavior with variation of JHC model constants, the model which used elastic modulus, the uni-axial compressive strength and density of the limestone were analyzed. Figure 7(a) shows the stress-strain curves with various constant $A$. Increment of $A$ increased the peak of the stress and the permanent plastic strain. Figure 7(b) shows the curves with various constant $B$. Increment of $B$ increased the peak of the stress but decreased the permanent plastic strain and the strain softening behavior. Figure 7(c) and (d) shows the stress-strain curves with various constant $F S$ and $T$, respectively. The differences are not visible with the variation of both constants. 


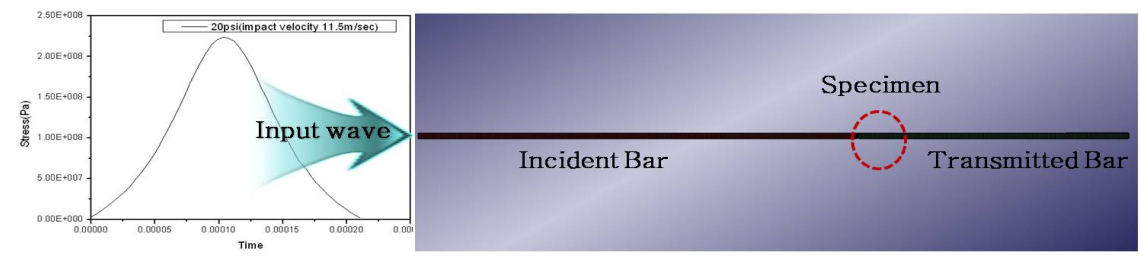

(a)

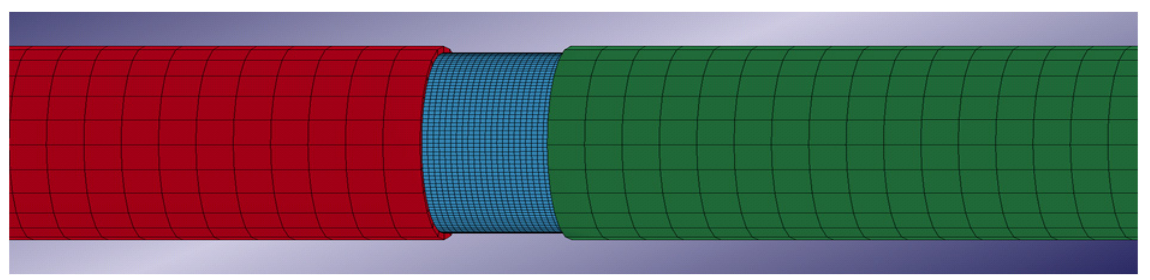

(b)

Figure 6: Detail of physical modeling of SHPB test. (a) Simulation model of the SHPB test; (b) Finite element layout of a sample and bars.

Modified JHC model constants as results from the sensitivity analyses were determined as listed in Table 4.

Table 4: $\quad$ Modified JHC model constants for modeling of limestone.

\begin{tabular}{|c|c|c|c|c|c|c|c|c|c|}
\hline $\begin{array}{c}\rho \\
\left(\mathrm{kg} / \mathrm{m}^{3}\right)\end{array}$ & $\begin{array}{c}\mathrm{F}_{\mathrm{C}} \\
(\mathrm{GPa})\end{array}$ & $A$ & $B$ & $\mathrm{C}$ & SFMAX & $\begin{array}{c}\mathrm{G} \\
(\mathrm{GPa})\end{array}$ & $D_{I}$ & $D_{2}$ & $N$ \\
\hline 2699 & 0.099 & 1 & 1.6 & 0.007 & 7 & 31 & 0.04 & 1 & 1.2 \\
\hline EFMIN & $\begin{array}{c}\mathrm{T} \\
(\mathrm{GPa})\end{array}$ & $\begin{array}{c}\mathrm{P}_{\mathrm{C}} \\
(\mathrm{GPa})\end{array}$ & $\mu_{C}$ & $\begin{array}{c}\mathrm{P}_{\mathrm{L}} \\
(\mathrm{GPa})\end{array}$ & $\mu_{L}$ & $\begin{array}{c}\mathrm{K}_{1} \\
(\mathrm{GPa})\end{array}$ & $\begin{array}{c}\mathrm{K}_{2} \\
(\mathrm{GPa})\end{array}$ & $\begin{array}{c}\mathrm{K}_{3} \\
(\mathrm{GPa})\end{array}$ & $\begin{array}{c}\mathrm{F}_{\mathrm{S}} \\
(\mathrm{GPa})\end{array}$ \\
\hline 0.01 & 0.0041 & 0.023 & 0.001 & 0.8 & 0.02 & 85 & -171 & 208 & -0.007 \\
\hline
\end{tabular}

Using modified JHC model constants, the SHPB tests of limestone were simulated and the strain waves on the incident and transmitted bars were obtained. The strain waves were used to calculate the stress-strain curves using Eq. (1) and (3). Figure 8 compared the stress-strain curves obtained from the numerical simulation with that obtained from SHPB tests. The numerical curves with different strain rates are coincident with the experimental curves. It is conceivable that the JHC concrete model should be used to simulate dynamic failure behavior of soft rock materials which show Class I failure pattern. 


\subsubsection{New equipment}

Some numerical simulations for the pendulum impact testing machine with new striker and target are carried out; the corresponding initial height of swing arm is $14.5 \mathrm{~g}$. By observing the results, the maximum stress takes place on the striker and target collision position. The maximum equivalent stress on the striker is about $1300 \mathrm{MPa}$, and on the target is bout $1100 \mathrm{MPa}$. The stress of other regions is too small. Figure 6 shows the acceleration curves of three positions tested by the three acceleration sensors. From the curves, we can see that the accelerations

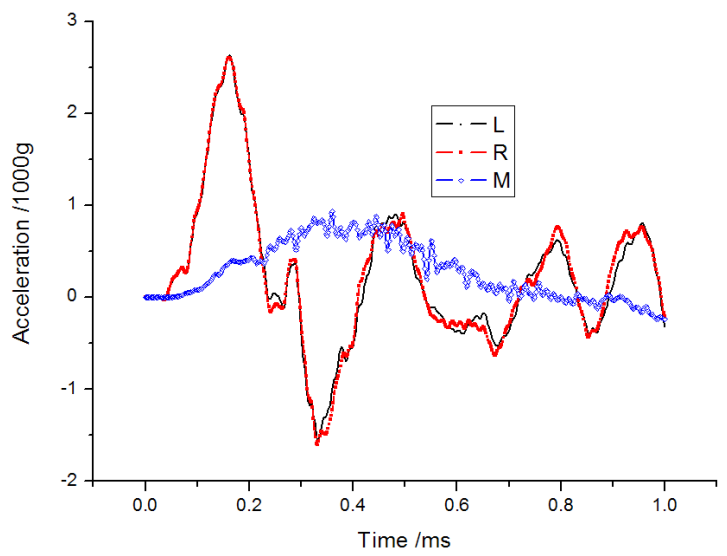

Figure 7: Acceleration curves of three measure points by experiments.

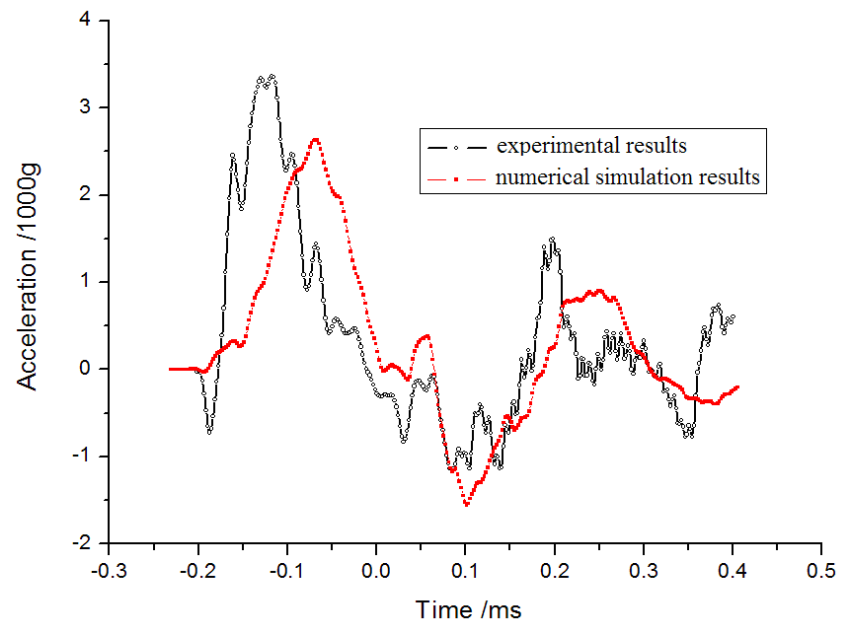

Figure 8: Acceleration curves comparison of measuring points L/R between experimental and numerical simulation results $(14.5 \mathrm{~g})$. 


\section{Conclusion}

The stress-strain curves of limestone under various strike velocities were obtained by SHPB tests adapting pulse shaping technique. It was conclude that limestone under dynamic impacts show Class I failure patterns which normally appear compression tests for solid materials such as limestone, tuff, sandstone, mudstone and concrete representing shear failure. Micro focus X-ray CT scanner was used non-destructively to observe the fracture patterns of tested samples. The internal cracks which are visible in the tested sample resulted in the permanent plastic strains which were represented in the stress-strain curves of the limestone samples. LS-DYNA was used for simulating SHPB dynamic impact test of limestone rocks with assumption of the wave propagation theory. In order to investigate the sensitivity of stress-strain behavior with variation of JHC model constants, the model which used elastic modulus, the uni-axial compressive strength and density of the limestone were analyzed. Using modified JHC model constants, the SHPB tests of limestone were simulated and the strain waves on the incident and transmitted bars were obtained. It is concluded that the JHC concrete model should be used to simulate dynamic failure behavior of limestone which show Class I failure pattern.

\section{Acknowledgements}

This work was supported by the Defense Research Laboratory Program of the Defense Acquisition Program Administration and the Agency for Defense Development of Republic of Korea.

\section{References}

[1] Bacon C., Separation of waves propagating in an elastic or viscoelastic Hopkinson pressure bar with three-dimensional effects, International of Impact Engineering, 22, pp. 55-69, 1999.

[2] Gomez, J., Shukla, A., Sharma, A., Photoelastic Evaluation of Stress Fields and Fracture during Dynamic Splitting Experiments, Journal of Testing and Evaluation 30(3), 186-196, 2002.

[3] Cho S.H., Cho S.K., Kim S.K., P C. \& Kaneko K., Experimental study on the dynamic damage mechanism of rocks under different impact loadings, Tunnel and Underground Space, 19(6), pp. 545-557, 2009.

[4] Cho S.H., Nakamura Y., Ogata Y., Mohanty B., Kitayama H. \& Kaneko K., Fracture processes of rocks in dynamic tensile-splitting test, the 1st Canada and U.S. Rock Mechanics Symposium, Vancouver, Canada., pp. 639-645, 2007.

[5] Kang M.S., Kang H.M., Kim S.K., Cheon D.S., Kaneko K., Cho S.H., Experimental study on deformation and failure behavior of limestones under dynamic loadings, Journal of Korean Society For Rock Mechanics, pp. 339$345,22(5), 2012$. 
[6] Holmquist T. J., Johnson G R., Cook W. H., A computational constitutive model for concrete subjected to large strain, high strain rates, and high pressure, 14th International Symposium on Ballistics Québec, Canada, pp. 26-29, 1993.

[7] Ma G.W. \& An X.M., Numerical simulation of blasting-induced rock fractures, International Journal of Rock Mechanics \& Mining Sciences 45(6) pp. 996-975, 2008.

[8] Kolsky H., An Investigation of the mechanical properties of materials at high rate of loading, Proceedings of the Physical Society, Section B62(11), pp. 676-700, 1949. 